\title{
NATURAL CONVECTION HEAT TRANSFER BETWEEN TWO CONCENTRIC AND ECCENTRIC OBLATE HEMI SPHEROIDS WITH DIFFERENT ELLIPTICAL RATIOS
}

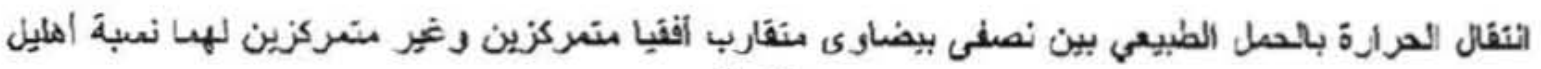 \\ متغيرة
}

El-Desouki Ibrahim Eid

Associate Prof., Mech. Dept., Faculty of Ind. Educ., Suez Canal University, Suez, EGYPT, 43515 , Suez.

\begin{abstract}
ملغص

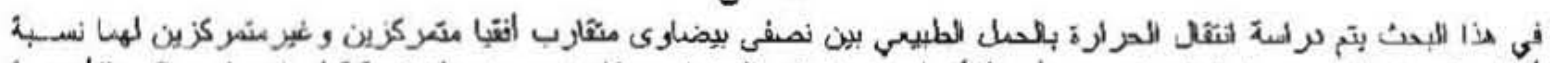

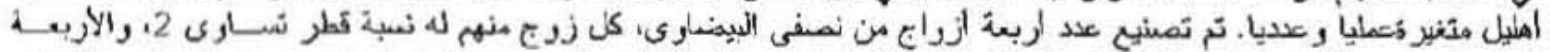
الزراج لهه نسب الشبل (صنر،

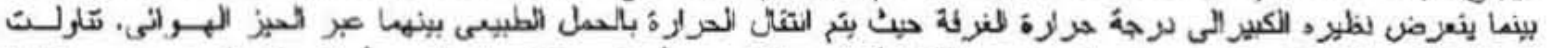

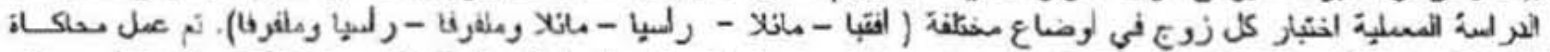

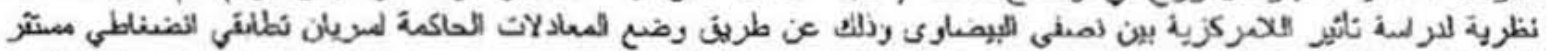

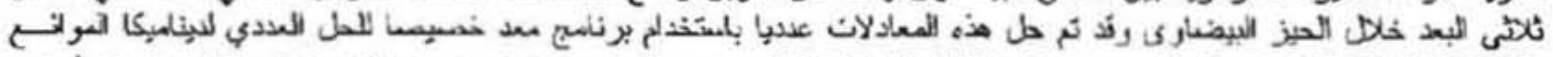
SLLENT-CFD

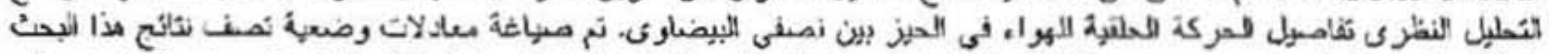

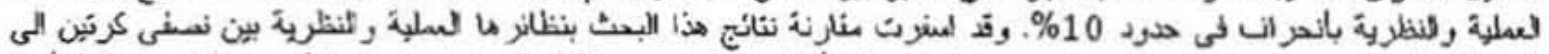

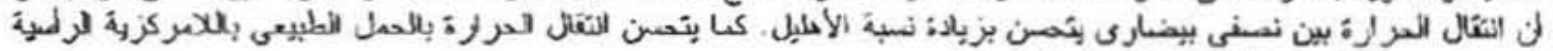

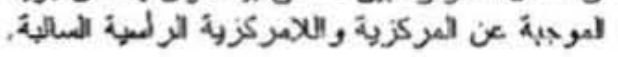

\begin{abstract}
ABSTRACX
In this paper, the natural convection heat transfer between a pair of concentric and eccentric oblate hemi-spheroids with different elliptical ratios was depicted experimentally and numerically. Four pairs of oblate hemi-spheroids having eltiptical ratios of $0.0,0.25,0.5,0.75$ and a diameter ratio of 2 for each pair were cut using the wirc-cut JSEDM CNC machining. The inner hemi-spheroid was heated while the outer one was exposed to the room temperature. The experimental tests scan the effect of the orientation modes (horizontal, inclined, vertical inclined revolved and vertical revolved) on the natural convection heat transfer between the inner and outer surfaces of cach pair. A mathernatical model was devoted for the case study to investigate the effect of the eccentricity on the thermal performance of such cases. The model was solved numerically using FLUENT CFD soiver. The CFD results were validated via corresponding experimental data. The temperature and velocity contours of the air gab were displayed to indicate the ring movement of the buoyancy driven air plume. The comparison among the results of the present attempt and those by the literature implied that; a notable increase in the natural convection heat transfer rates could be satisfied through the gabs among successive layers of hemi-spheroids having higher elliptical ratio rather than the hemi-spherical ones. Also, the positive vertical eccentricity shows remarked increase in natural convection heat transfer rates rather than both concentric and negative eccentric cases.
\end{abstract}

KEY WORDS: Natural Convection, Heat Transfer, Spheroids, Elliptical ratio, Orientation mode, CFD solvers. 


\section{INTRODUCTION}

Hemi-spheres and hemi-spheroids become popular in modern glazed buildings. Glazed buildings are useful in bringing daylight and solar heat to indoor space. For hemispheroids of multiple layers with different elliptical ratio, the natural convection heat transfer among these layers is often important in various applications such as; nuclear reactor design, aircraft cabin insulation, cooling of electronic equipments, thermal storage systems, solar encrgy collectors, heating heads of Stirling machines, gcophysical fields and eggs-white shell bodies. The present attempt aims at an adequate evaluation for the thermal performance of such applications that concerming natural convection heat transfer. An experimental investigation concerning natural convection heat transfer through air enclosed between two isothermal concentric spheres of various diameter ratios ranging from 1.19 to 3.14 at $2 \times 10^{4} \leq G r \leq 3.6 \times 10^{6}$ was provided by [1]. Nussclt-Grashof correlations were presented for the measured heat-transfer data for four different diameter ratios and the correlation fitting was within $15.5 \%$ deviation. Another experimental investigation concerns natural convection heat transfer between two isothermal concentric spheres of various diameter ratios ranging from 1.09 to 2.81 with water, two silicon oils yielding $4.7 \leq \operatorname{Pr} \leq 4148$ and $1.3 \times 10^{2} \leq \operatorname{Ra} \leq 5.8 \times 10^{4}$ was provided by [2]. A $\left(k_{e f} / k\right)-R a$ beat transfer correlation was presented for each of the three fluids individually within $13.4 \%$ deviation, A finite-difference solution for steady natural convective flow in a concentric spherical annulus with isothermal walls had been obtained by [3]. Results were presented for a diameter ratios of 2 and 3, Prandtl numbers of $0.02, \quad 0.7$ and 6 and $10^{2} \leq R a \leq 10^{6}$. Excellent agreement with previous experimental data was obtained. The transient laminar natural convection heat transfer of fluids between two concentric isothermal spheres was investigated theoreticaily by [4]. The fluids were assumed to be initially at rest and then the inner wall is subjected to a step change of temperature. The transient behavior of the flow field and the temperature distribution at different Rayleigh numbers and radius ratios were analyzed by finite difference methods. The results showed that the Rayleigh number and radius ratio have a profound influence on the temperature and flow fields. A transient analysis had been investigated numerically to determine the heat transfer by natural convection between two concentric spheres with isothermal boundary conditions by [5]. The inner and outer spheres were heated and cooled in a step-wise change of temperature. The analysis lets $10^{3} \leq R a \leq 10^{5}, P r=0.7$ and a radius ratio of 2 . The computations delivered general $\mathrm{Nu}-\mathrm{Ra}$ correlations. A numerical study on the heat transfer by laminar natural convection within multi-layer domes with uniform spacing heated from the oulside was done by [6]. The flow and temperature fields within the domed enclosure were obtained. Correlations for the heat transfer as a function of the dome shape and gap spacing among the layers were developed. The results showed that the convective heat transfer for fully hemi-spherical domes is $13 \%$ higher than that for low profile domes (caps) with small gap spacing and it increases for large gap spacing. The transient temperature and velocity profiles during therrmal processes of egg shell bodies filled with a viscous liquid had been studied by [7]. Sodium carboxylmethyl cellulose suspension was used as a fluid. It has properties similar to egg white shell. The partial differential equations governing the natural convection in a threedimensional geometry were solved with the computational fluid dymamic FLUENT package. It was observed that natural convection tends to force the slowest heating zone towards the bottom of the egg. The transient natural convection heat transfer had been analyzed for viscous fluids $(\operatorname{Pr}=158,405$ and 720$)$ in a spherical annulus, with $5 \times 10^{3} \leq R a \leq 6.5 \times 10^{4}$ and $a$ radius ratio of 2.0 by [8]. Another transient natural convection analysis between concentric spheres having a radius ratio of 2 
at $10^{3} \leq R a \leq 5 \times 10^{5}$ through micro-polar fluids (micro polar parameter is $k / \mu, 1 \leq k / \mu \leq 5$ ) had been investigated numerically by [9]. The results showed that the filling of a cavity with a micro polar fluid will improve the thermal energy storage performance because it keeps warmer than the one filled with Newionian fluid. The effects of height and radius ratios ( $H R$ and $P R, H R=H_{\text {olioder }} / r_{\text {aphen }}$ and $\left.P R=r_{\text {cense }} / r_{\text {sudver }}\right)$ had been investigated numerically to determine beat t.ansfer by natural convection between a sphere and vertical cylinder with isothermal boundary conditions, [10]. The inner sphere and outer vertical cylinder were heated and cooled in a step-wise change of temperature. The study delivered out empirical collations for a range of $10^{3} \leq R a \leq 10^{6}$ and $1.2 \leq H R=P R \leq S$.

The purpose of the current investigation is to depict experimentally the effect of the elliptical ratio of hemi-spheroids on the natural convection heat transfer between a pair of them. The elliptical ratio of the hemispheroid was changed four times $(0,0.25,0.5$ and 0.75). Also, the present work investigated experimentally the effect of the orientation modes (horizontal, vertical, inclined, inclined revolved and vertical revolved) on the natural convection heat transfer. Empirical correlations were devoled to describe the experimental results. The present study presents also the effect of both positive and negative vertical eccentricity on the natural convection heat transfer by using a mathernatical model. The model was solved numerically using the FLUENT CFD package. Verification of both experimental and numerical results was done to validate the numerical model. Comparisons were attempted among the results of the present work and those by the literature.

\section{EXPERIMENTAL WORK}

Referring to figure (1), the meridian planner ellipse bas a major axis $a$ and a minor one $b$. Oblate spheroid is the surface created by rotating the meridian ellipse about the major axis, If $b \prec a$, the spheroid is called oblate and if $b>a$, the spheroid is called prolate. The surface equation of the oblate spheroid is, [11]:

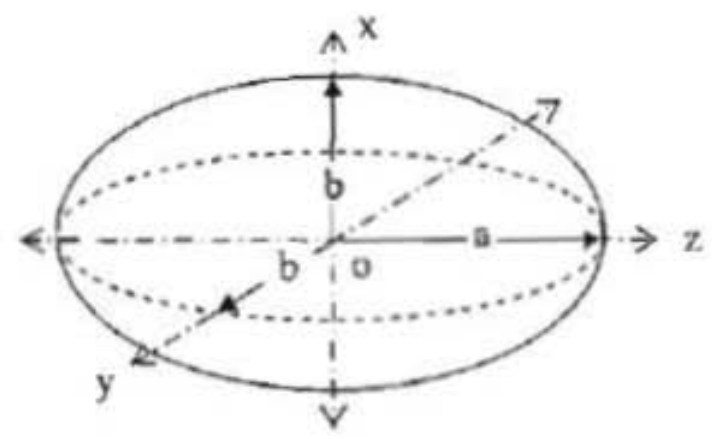

Figure (1), Geometry of the oblate spheroid.

$\frac{x^{2}+y^{2}}{b^{2}}+\frac{z^{2}}{a^{2}}=1$

The elliptical ratio of the spheroid is:

$$
\zeta=\sqrt{1-\frac{b^{2}}{a^{2}}}
$$

The surface area of the spheroid is:

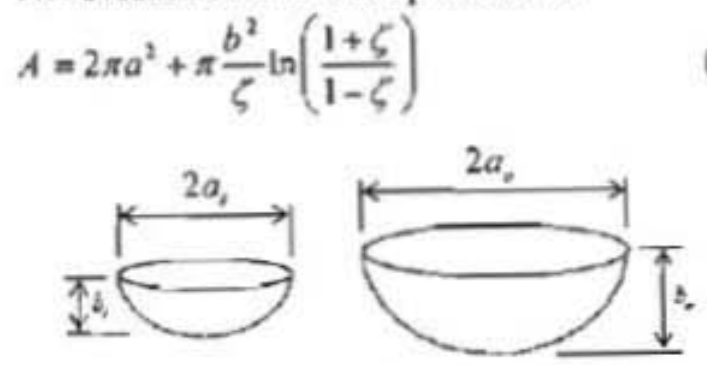

Figure (2), Pair of the hemi-spheroid.

Referring to figure (2), the dimensions and the elliptical ratio of the four tested pairs are listed in table (1).

Table (1), Dimensions of test specimens.

\begin{tabular}{|c|c|c|c|c|c|}
\hline \multirow{2}{*}{$\begin{array}{l}\text { Pair } \\
\text { No. }\end{array}$} & \multicolumn{4}{|c|}{ Dimensions in $\mathrm{cm}$. } & \multirow{2}{*}{$\begin{array}{l}\text { Elliptical } \\
\text { ratio, } \zeta\end{array}$} \\
\hline & $a$, & $b$ & $a_{0}$ & b. & \\
\hline 1 & 7.50 & 7.50 & 15.00 & 15.00 & 0.00 \\
\hline II & 7.50 & 7.26 & 15.00 & 14.52 & 0.25 \\
\hline III & 7.50 & 6.50 & 15.00 & 13.00 & 0.50 \\
\hline IV & 7.50 & 4.96 & 15.00 & 9.92 & $0 . \overline{75}$ \\
\hline
\end{tabular}

The wall thickness of each hemi-spheroid is $2.5 \mathrm{~mm}$. Also, the given dimensions are the inner dimensions of the large hemi-spheroid and outer ones for the small one. The four pairs were cut from pure aluminum by using the wire-cut JSEDM CNC machining, [12]. Referring to figure (3), the inner hemispheroid was internally heated by an electric 
nickel-chrome heater which was buried inside a typical small bakelite hemi-spheroid.

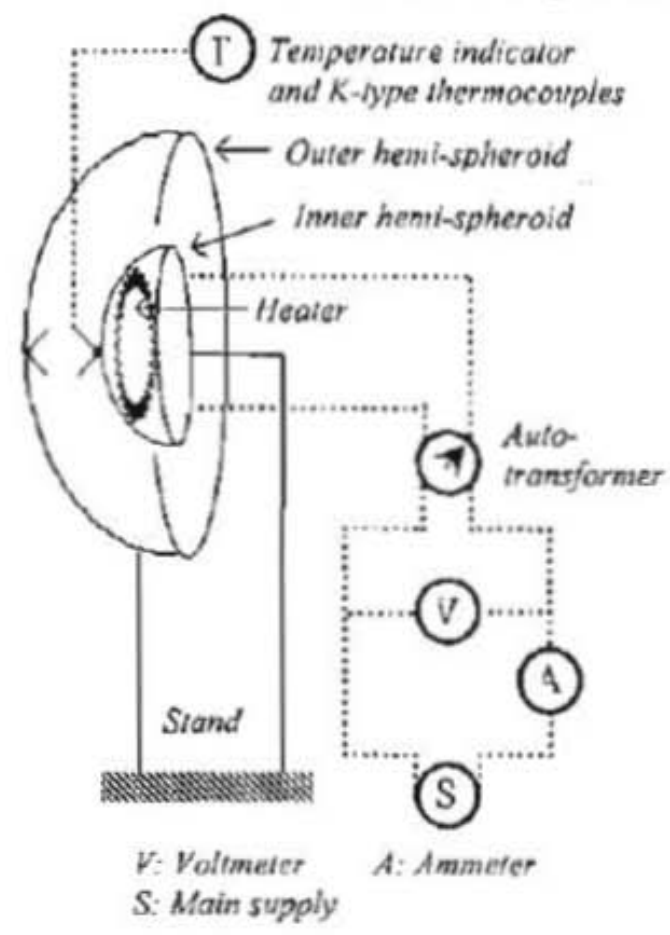

Figure (3), Main parts of the experimental test rig.

An electric insulation tape ivas covered the heater. The space between the heater and the inner surface of the small hemi-spheroid was filled with dry sand to avoid the convection currents and to sustain an almost uniform heat flux. Also, an asbestos layer having $1.0 \mathrm{~cm}$ thick was located at the flat end of the small hemi-spheroid to reduce the losses by conduction. Three $K$-type thermocouples were used to measure the temperature of the outer surface of the small bemi-spheroid. Five ones were used to measure the temperature of the inner surface of the large hemi-spheroid. Three ones were used to measure the temperature of the air gab between the two hemi-spheroids. Two ones measure the temperatures of both sides of the asbestos layer. One thermocouple was used to measure the room temperature of a closed laboratory. A digital temperature indicator having a resolution of $0.1^{\circ} \mathrm{C}$ was used to record the temperatures. The electric power consumed by the heater was controlled by an altering variance unit of $3000 \mathrm{VA}$ capacity. An ammeter of $0.01 \mathrm{~A}$ resolution and a volimeter of $0.1 \mathrm{~V}$ resolution were used to measure the electric power co.nsumed by the heater, [13]. The experimental work scans the effects of elliptical ratio, orientation modes (vertical, horizontal, inclined, inclined revolved and vertical revolved) as shown in Figure (4), on the natural convection heat transfer between a pair of concentric hemispheroids.

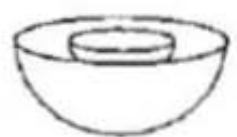

(a)

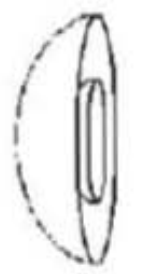

(c)

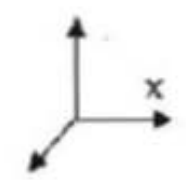

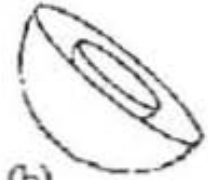

(b)

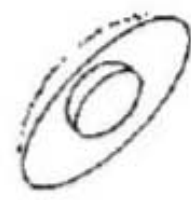

(d)

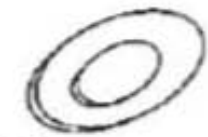

(e)
Figure (4), Orientations of the test specimen;

(a) Horizontal; $\left(\phi=0^{\circ}, p=0^{\circ}\right)$,

(b) Inclined; $\left(\phi=45^{\circ}, \varphi=0^{\circ}\right)$,

(c) Vertical; $\left(\phi=90^{\circ}, \varphi=0^{\circ}\right)$,

(d) Vertical revolved; $\left(\phi=0^{\circ}, \varphi=90^{\circ}\right)$, and

(e) Inclined revolved; $\left(\phi=0^{\circ}, \phi=45^{\circ}\right)$.

\section{EXPERIMENTAL DATA REDUCTION}

The main objective of this paper is to provide evidences about the parameters that create a stronget buoyancy-driven plume which results in higher heat transfer coefficient by natural convection in a space between a pair of concentric oblate hemi-spheroids having different elliptical ratios if they were oriented at different orientation modes. The heat transfer by natural convection can be evaluated as follows, [14 and 15]:

$$
Q_{\text {cosictios }}=Q_{\text {ional }}-Q_{\text {noisioe }}-Q_{\text {conduction }}
$$

Where; $Q_{\text {iven }}$ is the electrical power converted to heat by the electric heatet. The 
heat transfer by radiation from innet surface to outer one and to air can be found as follows:

$$
\begin{aligned}
& Q_{\text {retivion }}=\frac{\sigma A_{1}\left(T_{1}^{4}-T_{0}^{4}\right)}{\left(\frac{1}{\varepsilon_{1}}+\frac{\left(1-\varepsilon_{0}\right)}{\varepsilon_{0}}\right) \frac{A_{1}}{A_{0}}} \\
& +\frac{\sigma \varepsilon_{1} A_{1}\left(T_{i}^{4}-T_{3}^{4}\right)}{1+\varepsilon_{i}\left(\frac{A_{i}}{\pi\left(a_{0} b_{e}-a_{i} b_{1}\right)}-1\right)}
\end{aligned}
$$

The heat transfer by conduction from the asbestos layer covering the flat end of the small hemi-spheroid is as follows:

$Q_{\text {endwese }}=\frac{n a_{t} b_{i}\left(T_{a t, 1}-T_{a t s}\right)}{\delta_{a} / k_{a}}$

The average convective heat transfer cocfficient, average Nusselt number and Rayliegh number can be found as foliows:

$$
\begin{aligned}
& \vec{h}_{e}=Q_{\text {tumetien }} / A_{i}\left(T_{i}-T_{a}\right) \\
& \bar{N}_{u_{e}}=\frac{\bar{h}_{i} \ell}{k_{e}} \text { wbere; } \ell=b_{e}-b_{i} \\
& R a_{a}=\frac{g B\left(T_{i}-T_{e}\right) \ell^{\prime}}{g_{a} a_{e}}
\end{aligned}
$$

The air properties in the above equations are evaluated at the mean temperature, [16 and 17), $\left[\tau_{n}=\left(\tau_{1}+T_{2}\right) / 2\right]$.

\section{MATHEMATICAL MODEL}

The partial differential equations governing the air motion in a three-dimensional space due to natural convection heat transfer between a pair of bemi-spheres are the mass, momentum and energy equations. In case of an incompressible fluid flow having constant thermal and physical properties, except for Boussinesg approximation for density in the buoyancy term in momentum equation, these equations could be reduced in Cartesian coordinates as follows, [7]:

Continuity equation: $\frac{\partial u}{\partial x}+\frac{\partial v}{\partial y}+\frac{\partial w}{\partial z}=0$

Momentum equation in $x$-direction:

$$
\begin{aligned}
& \rho\left(u \frac{\partial u}{\partial x}+v \frac{\partial u}{\partial y}+w \frac{\partial u}{\partial z}\right)= \\
& -\frac{\partial p}{\partial x}+\mu\left(\frac{\partial^{2} u}{\partial x^{2}}+\frac{\partial^{2} u}{\partial y^{2}}+\frac{\partial^{2} u}{\partial z^{2}}\right)
\end{aligned}
$$

Momentum equation in $y$-direction:

$$
\begin{aligned}
& \rho\left(\mu \frac{\partial v}{\partial x}+v \frac{\partial v}{\partial y}+w \frac{\partial v}{\partial z}\right)= \\
& -\frac{\partial p}{\partial y}+\mu\left(\frac{\partial^{2} v}{\partial x^{2}}+\frac{\partial^{2} v}{\partial y^{2}}+\frac{\partial^{2} v}{\partial z^{2}}\right)+\rho g
\end{aligned}
$$

Momentum equation in z-direction:

$$
\begin{aligned}
& \rho\left(u \frac{\partial w}{\partial x}+v \frac{\partial w}{\partial y}+w \frac{\partial w}{\partial z}\right)= \\
& -\frac{\partial p}{\partial z}+\mu\left(\frac{\partial^{2} w}{\partial x^{2}}+\frac{\partial^{2} w}{\partial y^{2}}+\frac{\partial^{2} w}{\partial z^{2}}\right)
\end{aligned}
$$

Energy equation:

$$
\begin{aligned}
& \rho C,\left(u \frac{\partial T}{\partial x}+v \frac{\partial T}{\partial y}+w \frac{\partial r}{\partial z}\right)= \\
& \left(u \frac{\partial p}{\partial x}+v \frac{\partial p}{\partial y}+w \frac{\partial p}{\partial z}\right)-\left(\frac{\partial q_{r}}{\partial x}+\frac{\partial g_{r}}{\partial y}+\frac{\partial y_{r}}{\partial z}\right) \\
& +k\left(\frac{\partial^{2} T}{\partial x^{2}}+\frac{\partial^{2} T}{\partial y^{2}}+\frac{\partial^{2} T}{\partial z^{2}}\right)
\end{aligned}
$$

This model is provided to study the effect of the eccentricity between a pair of hemispheres on the natural convection heat transfer between them; when they were oriented in vertical positions as show is figure (5)

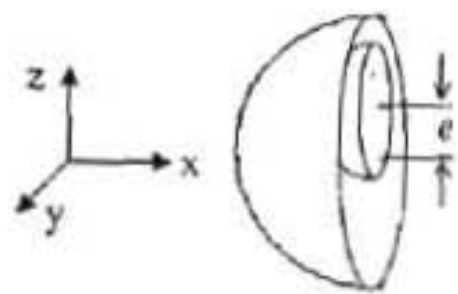

Figure (5), Two-eccentric bemi-spheres.

The boundary conditions for this mojel are:

- At the surface of the inner hemi-sphere;

$u=v=w=0, \quad q=$ const.

- At the surface of the outer hemi-sphere;

$u=v=w=0 ; \quad T=T$.

- A! the symmetry plane, $y=0$

$\frac{\partial u}{\partial y}=\frac{\partial T}{\partial y}=\frac{\partial v}{\partial y}=\frac{\partial w}{\partial y}=0$ 
These goveming equations are solved numerically using CFD FLUENT, [18 and 19]. The case study was drawn in Gambit and tetrahedral grids with small interval size were created and the previous boundary conditions were defined. This model was exported to the FLUENT CFD solver. The variation of the thermal properties of air with its temperature was taken into consideration to be piecewise polynomials. A segregated, implicit, 3-D, cell-based solver was defined. The gravity effect was considered. The CFD solver makes a number of iterations until the solution is converged. The numerical solution studied the effect of both positive and negative eccentricities;

\section{RESULTS AND DISCUSSION}

The transition from conduction to convection tegime between two concentric spheres ends at $R a=10^{5}$, [5]. In the present work, all tests were done for $R a \geq 1.34 \times 10^{5}$; therefore, the heat transfer in the case study falls in the convection regime. Figure (6) shows the average Nusselt number versus Rayliegh number for horizontal orientation mode $\left(\phi=0^{\circ}, \varphi=0^{\circ}\right)$, for the four tested pairs. Rayleigh number in the present work was calculated based on the characteristic length $\ell=b_{0}-b_{i}$, this clarifies that why the pair (IV) has lower values of Rayleigh number. From this figure, it is obvious that; at the same Rayleigh number, the pair (IV) shows a notable increase in Nussclet number rather than the other ones. This is due to, the small gab between the inner and outer surface results in an increase in the air velocity due to the relatively high temperature which reduces the air density in such narrow space. And as a consequence, a stronger upward buoyancy-driven plume could be created. In the results of the numerical model, figure (15) shows that; the air velocity is suddenly increase near to the inner surface and hence it reduces more in the gab to its lowest value near the gab center and it increases again to reach to higher value near the outer surface. Thus; the larger gab allows formation of cold air in space around the gab center. However, narrow gab reduces the formation of cold air and consequently the formed hot air will be driven upward. The same tendency was even more remarked in figures (7, 8, 9 and 10). Figure (11) shows Nusselt number versus Rayliegh number for the tested pair (I), for different orientation modes (horizontal, inclined and vertical). The inclined orientation shows a quite increase in the free convective heat transfer rather than both horizontal and vertical orientation modes. Figure (16) shows the path lines of air in a $y-z$ plane at $x=-1.5 \mathrm{~cm}$. At the upper half of the inner sphere and due to the high temperature, a high velocity flow is separated from the surface and escaping upward towards the outer surface. When it reaches the inner surface of the outer sphere and due to the low temperature, as shown in figure (17), it directs downward towards the lower half of the outer sphere. This will reduce the buoyancy driven upward piume for the vertical orientation mode. It should be emphasized that; this flow pattern likes the falling vortex-eddy type (postulated flow pattern). This reduction is somehow reduced for the three spheroid pairs as clear in figures $(12,13$ and 14$)$.

The previous experimental results were fitted to determine empirical correlations among Nusselt number, Rayleigh number and the elliptical ratio as follows:

$$
\begin{aligned}
& \overline{N u}=\mathrm{C}(R a)^{*}\left(\frac{1}{\zeta}\right)^{m} \\
& \text { For }\left\{\begin{array}{l}
1.34 \times 10^{5} \leq R a \leq 6.32 \times 10^{6} \\
0<\zeta \leq 0.75
\end{array}\right.
\end{aligned}
$$

Where; the constants $\mathrm{C}, \mathrm{n}$ and $\mathrm{m}$ are tabulated as follows:

\begin{tabular}{|c|c|c|c|}
\hline Orientation & \multicolumn{2}{|c|}{ Constants } & Deviation \\
\hline \multirow{3}{*}{$\begin{array}{l}\text { Horizontal; } \\
\left(\phi=0^{\circ}, \phi=0^{\circ}\right)\end{array}$} & C & 0.2360 & \multirow{3}{*}{ $\pm 11.7 \%$} \\
\hline & $\mathbf{n}$ & 0.2425 & \\
\hline & $\mathrm{m}$ & 0.1371 & \\
\hline \multirow{3}{*}{$\begin{array}{l}\text { Inclined; } \\
\left(\phi=45^{\circ}, \varphi=0^{\circ}\right)\end{array}$} & C & 0.2371 & \multirow{3}{*}{ $\pm 14.2 \%$} \\
\hline & $\mathrm{n}$ & 0.2489 & \\
\hline & $\mathrm{m}$ & $0.138 !$ & \\
\hline
\end{tabular}

Table (2), Constants of the empirical correlations. 


\begin{tabular}{|c|c|c|c|}
\hline \multirow{3}{*}{$\begin{array}{l}\text { Vertical; } \\
\left(\phi=90^{\circ}, \varphi=0^{\circ}\right)\end{array}$} & C & 0.2201 & \multirow{3}{*}{ $\pm 13.0 \%$} \\
\hline & $\mathrm{n}$ & 0.2308 & \\
\hline & $\mathrm{m}$ & 0.2077 & \\
\hline \multirow{3}{*}{$\begin{array}{l}\text { Vertical revolved; } \\
\left(\phi=0^{\circ}, \phi=90^{\circ}\right)\end{array}$} & C & 0.2348 & \multirow{3}{*}{ $\pm 12.3 \%$} \\
\hline & n & 0.2349 & \\
\hline & $\mathrm{m}$ & 0.1506 & \\
\hline \multirow{3}{*}{$\begin{array}{l}\text { Inclined revolved; } \\
\left(\phi=0^{\circ}, \phi=45^{\circ}\right) .\end{array}$} & C & 0.2628 & \multirow{3}{*}{ $\pm 11.8 \%$} \\
\hline & $\mathrm{n}$ & $0.24 \overline{89}$ & \\
\hline & $\mathrm{m}$ & 0.2415 & \\
\hline
\end{tabular}

The numerical results are presented for the case study to investigate the effect of both positive and negative eccentricity for a pair of hemi-spheres having the same dimensions of both ones that were tested experimentally for vertical orientation mode. As the surface areas of the hemi-sphere pair are not equal the non-uniform tetrahedral meshing scheme should be used, figure ( 18 ). The CFD model reported the convective heat transfer coefficient which is used in Nusselt number calculations and it also reported the air temperature from its average volume-integral which is used for Raylcigh calculations. The numerical model was validated by comparing its results that were obtained for a pair of concentric hemi-spheres when they oriented vertically with those from the experimental tests. Figure (19) shows a quite agreement between the results of both numerical solution and experimental data. Figure (20) shows the temperature contours on three successive surfaces along $x$-direction. The temperature of inner hemi-sphere edge is higher than that of the outer hemi-sphere and it is obvious that the upper edge of the inner hemi-sphere has the highest temperature and its lower edge has the lowest temperature and the v.sa versa for air density. Due to the effect of gravity, the air near the surface of inner hemi-sphere flows upward about its surface. The hotter air meets at the top edge of inner hemi-sphere and creates a hot boundary layer. As the inner hemi-sphere surface was kept hotter, the momentum of the created upward buoyant plume keeps the upwasd air movement to meet the inside surface of outer hemi-sphere. The temperature of outer hemi-sphere is lower, and due to the effect of the convective heat transfer from the outer surface of the outer hemi-sphere, the air on its inside surface is cooled and its density becomes higher. Thus, the air near the outer hemi-sphere flows downward about its surface. At the steady state, the air reaches the bottom surface of outer sphere and does not rise to form a stagnation zone. Thus, a moving enclosed ring of air will appear as clear in figure (21). Referring to figures (22 and 23), for positive eccentricity $(e=+2.5 \mathrm{~cm}$ or $e / 1=+0.3333)$ the air has higher tensprature at the top edge of the inner hemi-sphere and it has also a quite little temperatures at the bottom edge of the outer hemi-sphere. This produces a quitc stronger upward plume rather than that of concentric hemi-spheres. Temperature and velocity magnitude versus $y$-axis in the meridian ellipse at three local z-levels are clear in figures (24 and 25). Figure (25) shows the highest value of velocity at the top vertex of the inner hemi-sphere and it reduces along the gab distance in $y$-direction. Such plots may be multifold the streamvortices formation. For two eccentric hemispheres $(e=-2.5 \mathrm{~cm}$, negative eccentricity), the area above inner sphere is larger and it has a disadvantage of natural convection heat transfer as it is quite cold as shown in figure (26). The velocity of air becomes quile greater at bottom narrow space rather than that at the top wide space as shown in figure (27). Also, a very small stagnation zone was formed at the upper edge of the outer hemisphere. Referring to figures (28 and 29), the effect of both positive and negative eccentricities on free convection heat transfer is clear. A correlation among Nusselt number, Rayleigh rumber and eccentricity was deduced as follows:

$$
\overline{N u}=\mathrm{C}(R a)^{n}(e / \ell)^{n} \text { For } 10^{5} \leq R a \leq 10^{\top}
$$

Where; the constants $C, \mathrm{n}$ and $\mathrm{m}$ are tabulated as follows:

Table (3), Constants of the empirical correlation.

\begin{tabular}{|l|c|c|c|}
\hline Eccentricity & \multicolumn{2}{|c|}{ Constants } & Deviation \\
\hline \multirow{3}{*}{ Positive eccentricity } & $\mathrm{C}$ & 0.2201 & \\
& $\mathrm{n}$ & $0.23 \mathrm{C} 8$ \\
\cline { 2 - 3 } & $\mathrm{4}$ & \multirow{3}{*}{ $\pm 1.3 \%$} \\
\cline { 2 - 3 } & $\mathrm{m}$ & -0.1085 & \\
\hline
\end{tabular}




\begin{tabular}{|c|c|c|}
\hline \multirow{3}{*}{ Negative eccentricity } & $\mathrm{C}$ & 0.2201 \\
\cline { 2 - 3 } & $\mathrm{n}$ & 0.2308 \\
\cline { 2 - 3 } & \multirow{2}{*}{ $\pm 1.8 \%$} & 0.1371 \\
&
\end{tabular}

\section{COMPARISON AMONG PRESENT WORK AND PREVIOUS WORKS}

A comparison among the experimental results of the present work and the experimental results of the previous work will be discussed in this section. Another comparison between the numerical predictions of the present work and precorrelated numerical data in the literature will be also clarified.

An experimental investigation between two concentric spheres of various diameter ratios and $2 \times 10^{4} \leq G r \leq 3.6 \times 10^{6}$ was provided by [1]. The data were correlated as:

$$
\overline{N u}=0.332 G r^{0.27}\left(\ell / r_{l}\right)^{0.517}
$$

A CFD solution for natural convective flow in a concentric spherical annulus had been obtained by [3]. Results were presented for a diameter ratio of 2 and 3, Prandtl numbers of 0.02, 0.7 and 6 and $10^{2} \leq R a \leq 10^{6}$.

An analysis had been investigated numerically to determine the heat transfer by natural convection between concentric spheres by [5], at $\mathrm{Pr}=0.7$ and a radius ratio of 2 . The computations were correlated as:

$\overline{\mathrm{Nu}}=0.21 R a^{0.24}$

A numerical study of heat transfer by natural convection within multi-layer domes having uniform spacing was done by [6]. Another study was done by [10] and its predictions were correlated as:

$\overline{N u}=0.206 R a^{0.28153}$

The experimental data of $[20]$ were correlated as:

$$
\overline{N u}=0.74(1 /(1+P r))^{0.25}\left(R a^{*}\right)^{0.25}
$$

The experimental results of the present work of four pairs of hemi-spheroids having different elliptical ratios when they were oriented as inclined and revolved, i.e. $\phi=0^{\circ}, \varphi=45^{\circ}$ were plotted as shown in figure (30). Also, the numerical CFD results for a pair of hemi-spheres when they were oriented vertically, i.e. $\phi=90^{\circ}, \varphi=0^{\circ}$ with positive and negative eccentricities were plotted in the same figure. From this figure, it is clear that, the increase in the elliptical ratio of the hemi-spheroids results in a remarkable increase in the convective heat transfer. In other words, the increase in the elliptical ratio of the oblate successive layers of concentric hemi-spheroids can satisfy higher convective heat transfer rather than those having hemi-spherical surfaces. Also, the comparison among the experimental and CFD results of the present work and those by the literature for the case of natural convection heat transfer between a pair of concentric hemi-spheres shows a notable fairly good agreement.

\section{CONCLUSIONS}

This paper reports the results of a study of natural convection heat transfer between pairs of concentric and vertically eccentric hemi-spheroids having a radius ratio of 2.0 with different elliptical ratio $(0,0.25,0.50$ and 0.75 ). Eight geometrical shapes for four pairs of hemi-spheroid were drawn on a PC and were manufactured by using $\mathrm{CNC}$ wirecut machining. The experimental tests were conducted for each pair such as the inner small hemi-spheroid is heated and the outer one is non-heated and it was exposed to ambient. Each pair of hemi-spheroids was tested experimentally at different orientation mode. A mathematical model was formulated to predict the natural convection of air inside the space between a pair of concentric and either positive eccentric or negative eccentric hemi-spheres. The model was solved numerically using the FLUENT CFD package. The main conclusions of the present work can be summarized as follows:

1. Natural convective heat transfer in the space between two concentric hemispheroids can be increased by increasing the elliptical ratio with an approximate percent as follows;

\begin{tabular}{|c|c|c|c|}
\hline Elliptical ratio, $z$ & 0.25 & 0.50 & 0.75 \\
\hline $\begin{array}{c}\text { Percentage } \\
\text { increase in Nu. }\end{array}$ & $8.77 \%$ & $19.56 \%$ & $28.77 \%$ \\
\hline
\end{tabular}


2. The situation of a pair of hemi-spheroids such as the minor axis of its meridian section is inclined to horizontal plane and the major axis is parallei to the horizontal plane produces stronger buoyancy upward driven plume and resulted in higher free convective heat transfer rates rather than other situations.

3. The situation of a pair of hemi-spheroids such as the minor axis of the meridian section is parallel to horizontal plane and the major axis is perpendicular to the horizontal plane resulted in lower free convective heat transfer rates, so, it may be preferred for thermal energy storage applications.

4. The validated numerical CFD approach shows that the positive eccentricity results in higher free convective heat transfer rates between a pair of hemispheres rather than both concentric and negative eccentric cases.

5. The present CFD model can be used to predict the thermal flow characteristics for the case study with different fluids having different Prandtl number.

NOMENCLATURE

\begin{tabular}{|c|c|c|c|c|c|}
\hline$\frac{\text { Symbol }}{A}$ & $\frac{\text { Description }}{\text { Surface area }}$ & $\frac{\text { Unit }}{m^{2}}$ & $\frac{\text { Symbol }}{Q}$ & $\begin{array}{l}\text { Description } \\
\text { Heat transfer rate }\end{array}$ & $\frac{\text { Unit }}{\psi}$ \\
\hline$a$ & Major axis length & $m$ & q. & Heat flux & $W / m^{2}$ \\
\hline$b$ & Minor axis length & $m$ & $R a$ & Rayleigh number & \\
\hline$e$ & Eccentricity & $m$ & $R a^{*}$ & $0.5 \ell R a$ & \\
\hline C & Specific heat & $J / \mathrm{kg} \cdot K$ & & $\left(b_{1} b_{0}\right)^{4}\left(\left(b_{1}\right)^{-14}+\left(b_{0}\right)^{-14}\right)^{3}$ & \\
\hline $\begin{array}{l}g \\
h\end{array}$ & $\begin{array}{l}\text { Gravity acceleration } \\
\text { Heat transfer coefficient }\end{array}$ & $\mathrm{m} / \mathrm{s}^{2}$ & $r$ & Radius & $m$ \\
\hline$k$ & Thermal conductivity & $W / m \cdot K$ & $T$ & Temperature & $\kappa$ \\
\hline$u, \mathrm{v}, w$ & Velocity components & $m / s$ & $t$ & Time & $s$ \\
\hline $\begin{array}{l}x, y, z \\
\zeta\end{array}$ & $\begin{array}{l}\text { Cartesian coordinates } \\
\text { Elliptical ratio }\end{array}$ & $m$ & $\varnothing$ & $\begin{array}{l}\text { Angle of inclination of } \\
\text { major axis to horizontal. }\end{array}$ & Degree \\
\hline$\alpha$ & $\begin{array}{l}\text { Thermal diffusivity } \\
\text { Volume coefficient of }\end{array}$ & & $\varphi$ & $\begin{array}{l}\text { Angle of inclination of } \\
\text { minor axis to horizontal }\end{array}$ & Degree \\
\hline & expansion & $K^{-1}$ & $\ell=b_{0}-b_{1}$ & Characteristic length & $m$ \\
\hline$\delta$ & Thickness & $m$ & $\mu$ & Dynamic viscosity & Pa.s \\
\hline$\varepsilon$ & Surface cmissivity & & $\vartheta$ & Kinematical viscosity & $m^{2} / s$ \\
\hline $\operatorname{Pr}$ & Prandtl number & & $\rho$ & Density & $\mathrm{kg} / \mathrm{m}^{2}$ \\
\hline$p$ & Pressure & Pa. & $\sigma$ & Stefan-Boltzman constant & $W / m^{2} K^{4}$ \\
\hline
\end{tabular}

Subscripts

\begin{tabular}{|c|c|c|c|c|c|}
\hline$\frac{\text { Symbol }}{a}$ & Description & $\frac{\text { Symbol }}{i}$ & $\frac{\text { Description }}{\text { Inner hemi-spheroid }}$ & $\frac{\text { Symbol }}{r}$ & $\frac{\text { Description }}{\text { Radiation }}$ \\
\hline as & Asbestos & $O$ & Outer hemi-spheroid & & \\
\hline
\end{tabular}

\section{REFERENCES}

f. Bishop, E. H., Mack, L R. and Scanlan, J.A., (1966), Heat Transfer by Natural Convection between Concentric Spheres, Int. J. Heat Mass Transfer, Vol.9, pp.649-662.
2. Scanlan, J. A., Bishop E. H. and Powe, R. E., (1970), Natural Convection Heat Transfer between Concentric Spheres, Int. J. Heat Mass Transfer, Vol.13, pp.1857-1872. 
3. Garg, V.K., (1992), Natural Convection between Concentric Spheres, Int. J. Heat Mass Transfer, Vol. 35 , No.8, pp.1935-1945.

4. CHU, H. and LEE, T., (1993), Transient Natural Convection Heat Transfer between Concentric Spheres, Int. J. Heat Mass Transfer, Vol. 36, No. 13, pp. 3159-3170.

5. Chiu, C.P. and Chen, W.R., (1996), Transient Natural Convection Heat Transfer between Concentric and Vertically Eccentric Spheres, Vol. 39. No. 7, pp. 1439-1452.

6. Laouadi, A. and Atif, M.A., (2001), Natural Convection Heat Transfer within Multi-Layer Domes, Int. J. of Heat and Mass Transfer No. (44), pp. 1973-1981.

7. Denys, S., Pieters, J.G., and Deweltinck, K., (2004), Computational Fluid Dynamics Analysis of Combined Conductive and Convective Heat Transfer in Model Eggs, Journal of Food Eng. No. (63), pp. 281-290.

8. Wu, H.W. Tsai, W.C. and Chou, H.M., (2004), Transient Natural Convection Heat Transfer of Fluids with Variable Viscosity between Concentric and Vertically Eccentric Spheres, Int. J. of Heat and Mass Transfer No. (47), pp.1685-1700.

9. Chen, W.R., (2005), Transient Natural Convection of Micropolar Fluids between Concentric and Vertically Eccentric Spheres, Int. J. of Heat and Mass Transfer No. (48), pp. 19361951

10. Chen, W.R., (2007), A Numerical Study of Laminar Free Convection Heat Transfer between Inner Sphere and Outer Vertical Cylinder, Int. J. of Heat and Mass Transfer No. (50), pp. 2656-2666
11. Bruckenstein, S. and Janiszewska, J., Diffusion Currents to (Ultra) Microelectrodes of Various Geometries/Ellipsoids, Spheroids and Elliptical 'Disks', Journal of Electroanalytical Chemistry, 538-539 (2002) $3 / 12$

12. JSEDM, WIRECUT EDM, Operation Instruction, Jiann Sheng Machinery \& Electric Industrial Co., LTD.

13. Holman, J.P., (2001), Experimental Methods for Engineers, McGraw-Hill Int. Edition, Seventh Edition, New York, USA.

14. Holman, J.P., (2002), Heat Transfer, McGraw-Hill Co., Ninth Edition, New York, USA.

15. Incropera, F.P. and Dewitt, D.P., (1990), Fundamentals of Heat and Mass Transfer, John Wiley \& Sons, Inc., Third Edition, New York, USA.

16. Shames, 1.H., (1992), Mechanics of Fluids, McGraw-Hill Inc., Third Edition, New York, USA.

17. Cengel, Y. A. and Boles, M. A., (1998), Thermodynamics: An Engineering Approach, McGraw-Hill Co., Third Edition, NY. USA.

18. Versteeg, H. K and Malalasekera, W., An Introduction to Computation Fluid Dynamics, The Finite Volume Method, John Wiley, Sons Inc., 605 Third Avenue, New York, USA, (1995).

19. FLUENT, Fluent user's guide, Lebanon, Fluent Inc., USA, (2000).

20. Raithby, G.D. and Hollands, K.G.T., (1975), A General Method of Obtaining Approximate Solutions to Laminar and Turbulent Free Convection Problems, Adv, Heat Transfer 11, pp.265-315. 


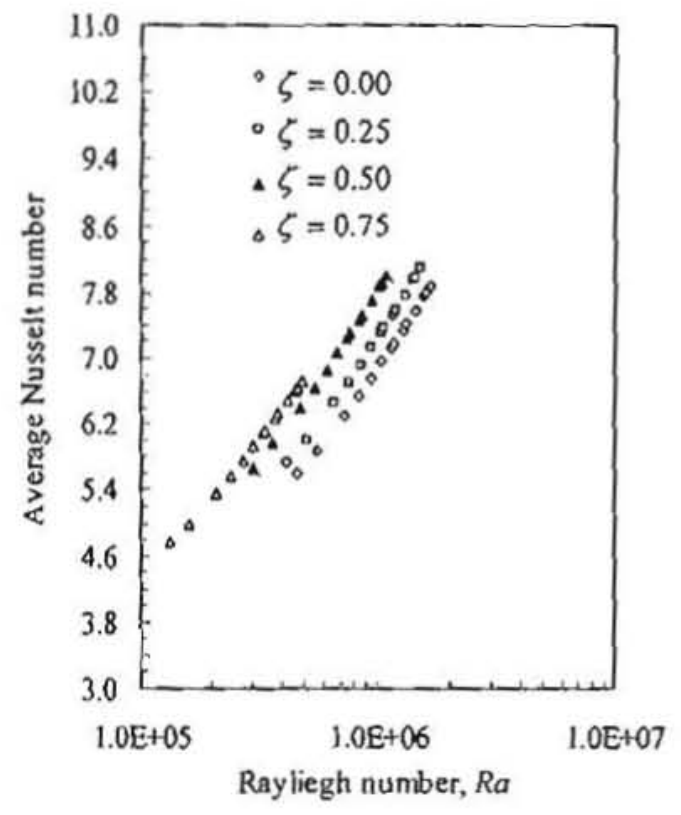

Figure (6), Average Nusseit number versus Rayliegh number for horizontal orientation $\left(\phi=0^{\circ}, \varphi=0^{\circ}\right)$, for the four tested pairs.

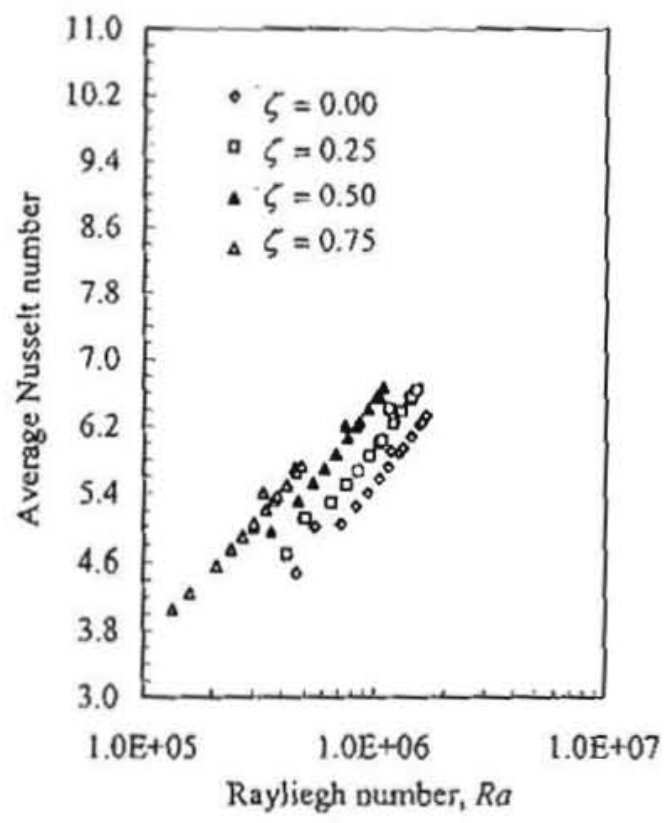

Figure (8), Average Nusselt number versus Rayliegh number for vertical orientation $\left(\phi=90^{\circ}, \varphi=0^{\circ}\right)$, for the four tested pairs.

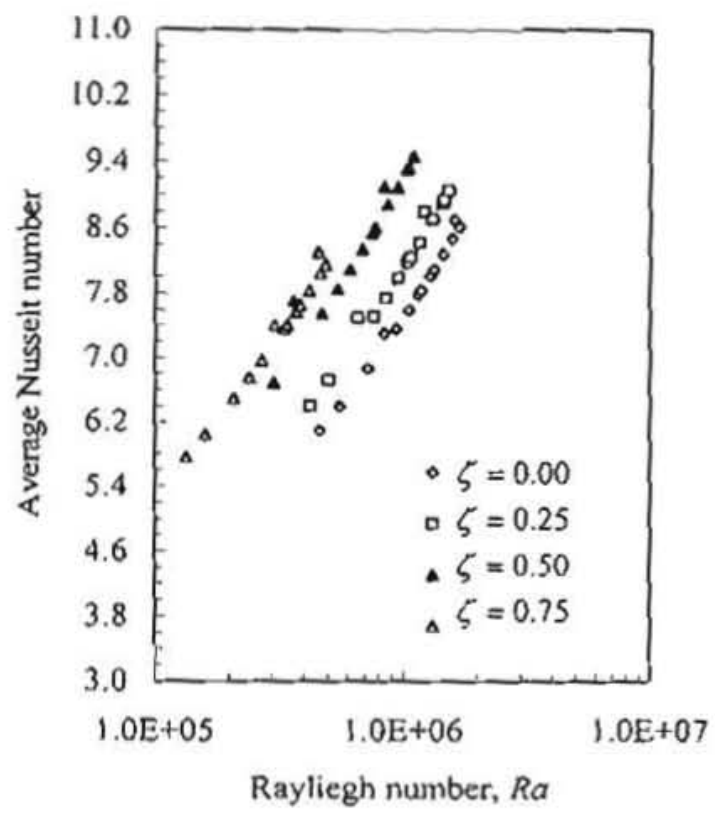

Figure (7), Average Nusselt number versus Rayliegh number for inclined orientation $\left(\phi=45^{\circ}, \varphi=0^{\circ}\right)$, for the four tested pairs.

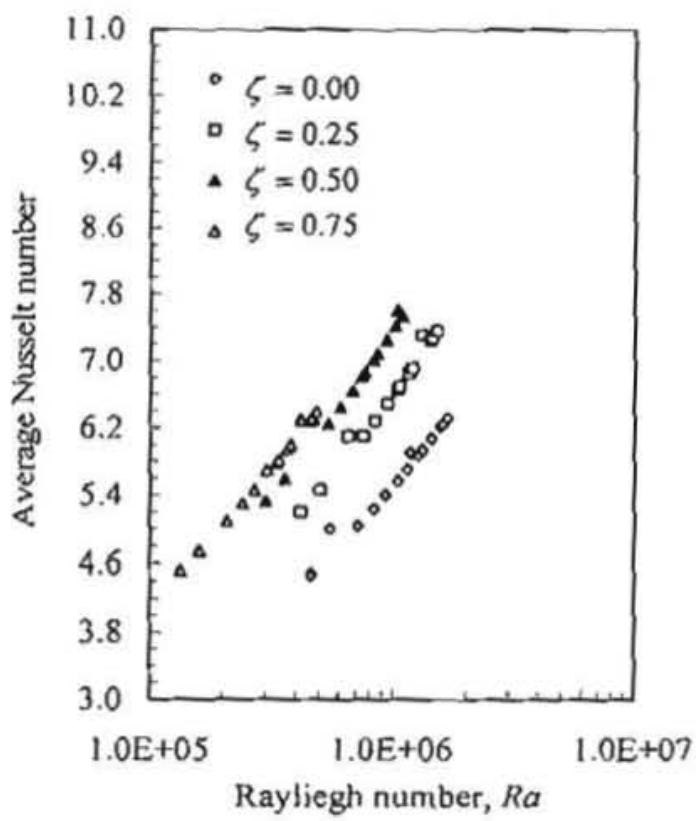

Figure (9), Average Nusselt number versus Rayliegh number for vertical orientation $\left(\phi=0^{\circ}, \varphi=90^{\circ}\right)$, for the four tested pairs. 


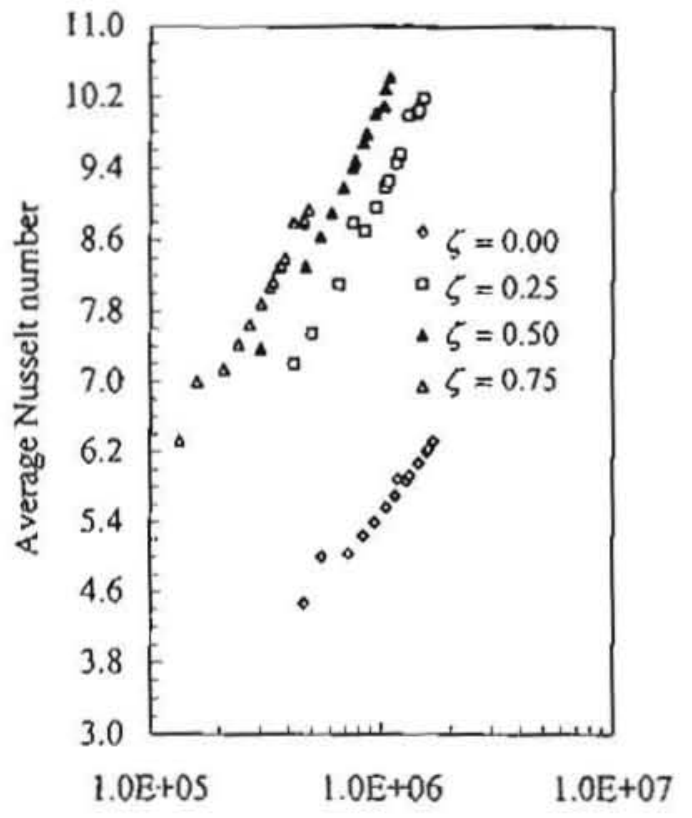

Rayliegh number, $R a$

Figure (10), Average Nusselt number versus Rayliegh number for inclind revolved orientation $\left(\phi=0^{\circ}, \varphi=45^{\circ}\right)$, for the four tested pairs.

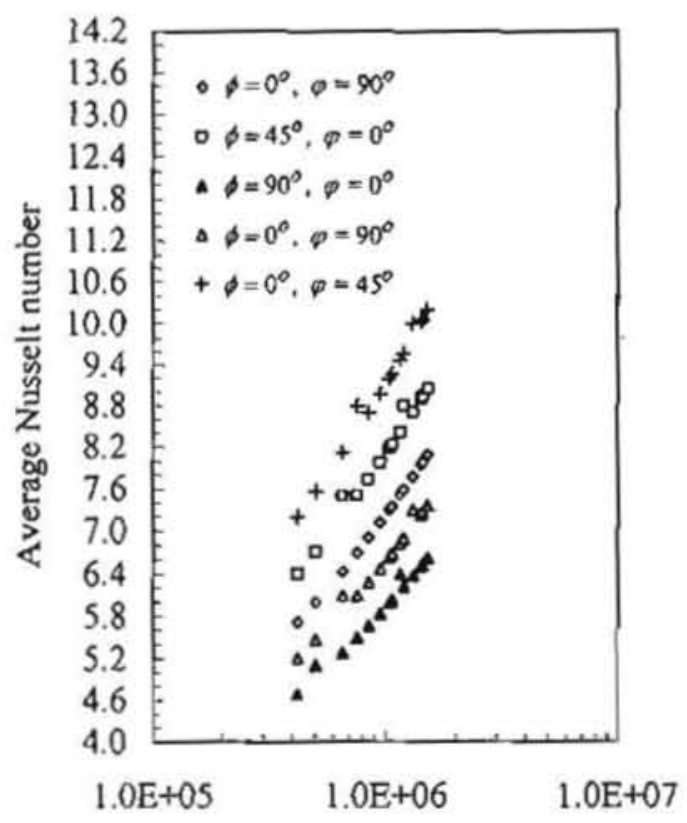

Rayliegh number, $R a$

Figure (12), Average Nusselt number yersus Rayliegh number for the tested pair No. II for different orientation modes.

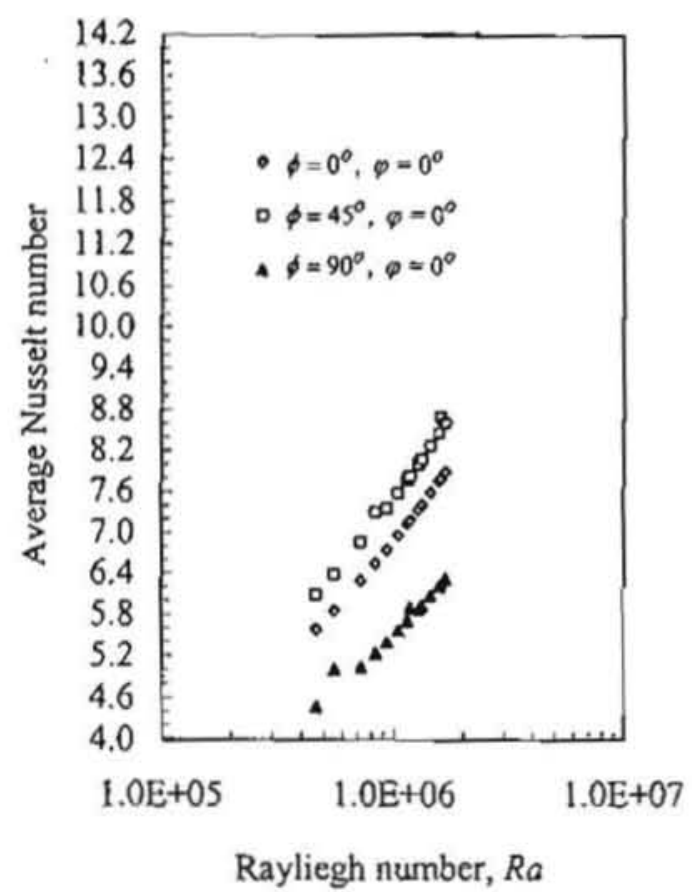

Figure (11), Average Nusselt number versus Rayliegh number for the tested pair No. I for different orientation modes.

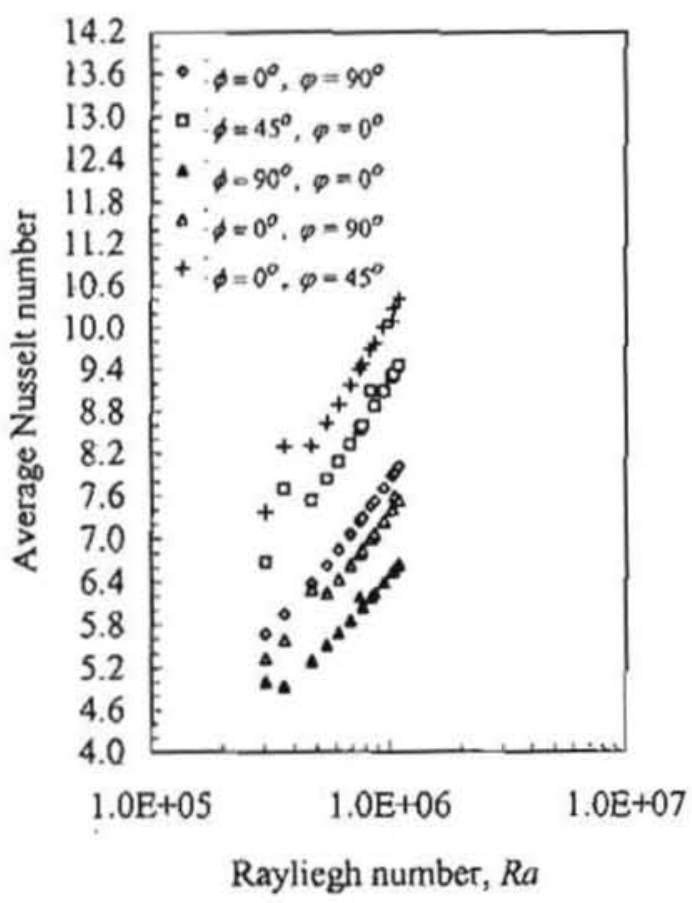

Figure (13), Average Nusselt number versus Rayliegh number for the tested pair No. III for different orientation modes. 


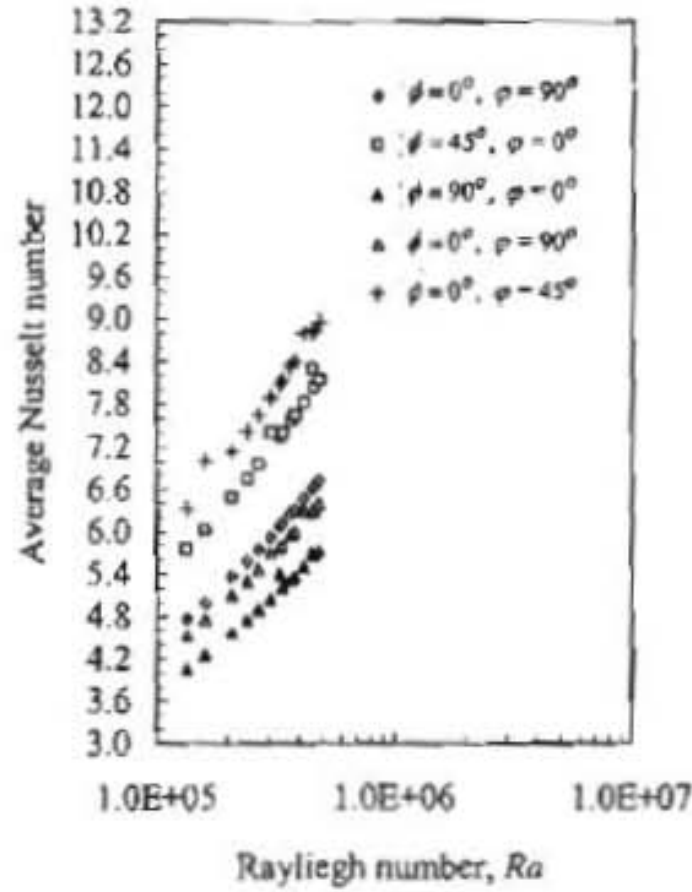

Figure (14), Average Nusselt number versus Rayliegb number for the tested pair No. IV for different orientation modes.

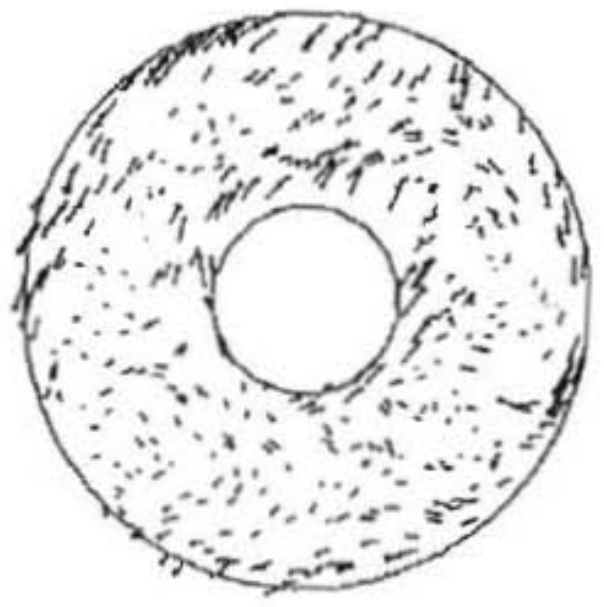

Figure (16), Path lines of air in a $y-z$ piane where $x=-1.5 \mathrm{~cm}$.

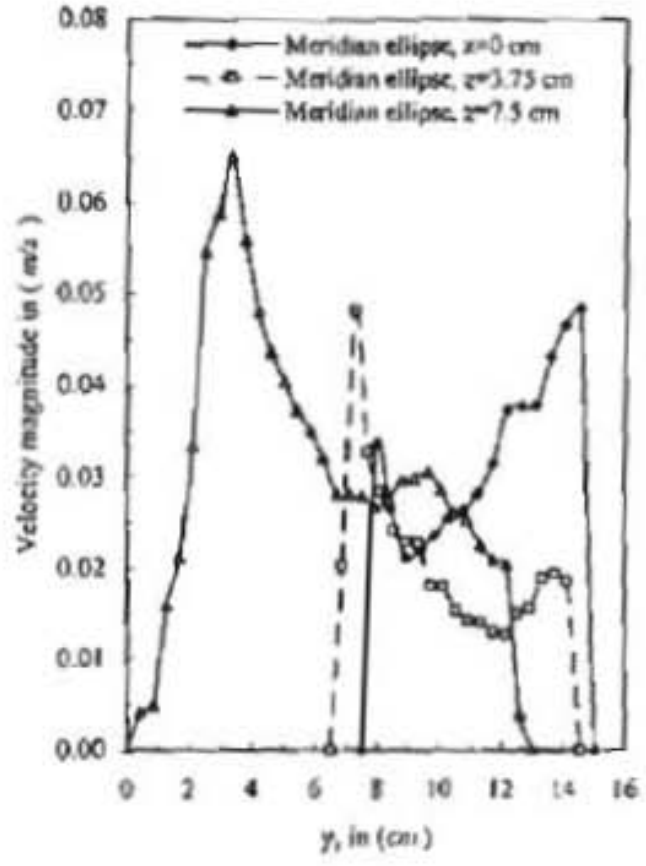

Figure (15), Velocity magnitude versus yaxis in the meridian ellipse at three local $z$. levels for two concentric hemi-spheres.

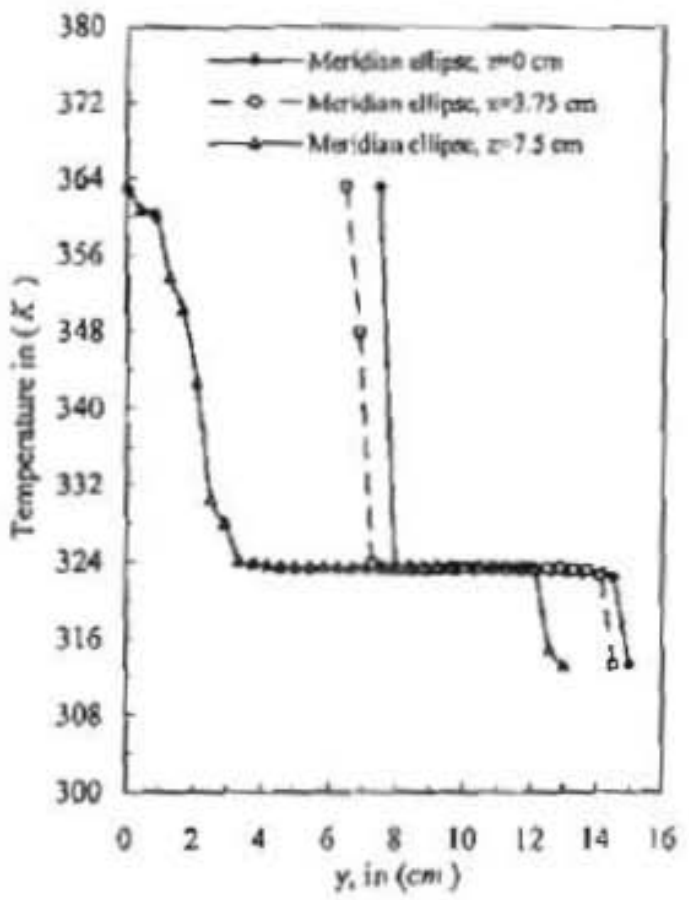

Figure (17), Local temperature versus y-axis at three $\mathrm{z}$ values in the meridian ellipse. 

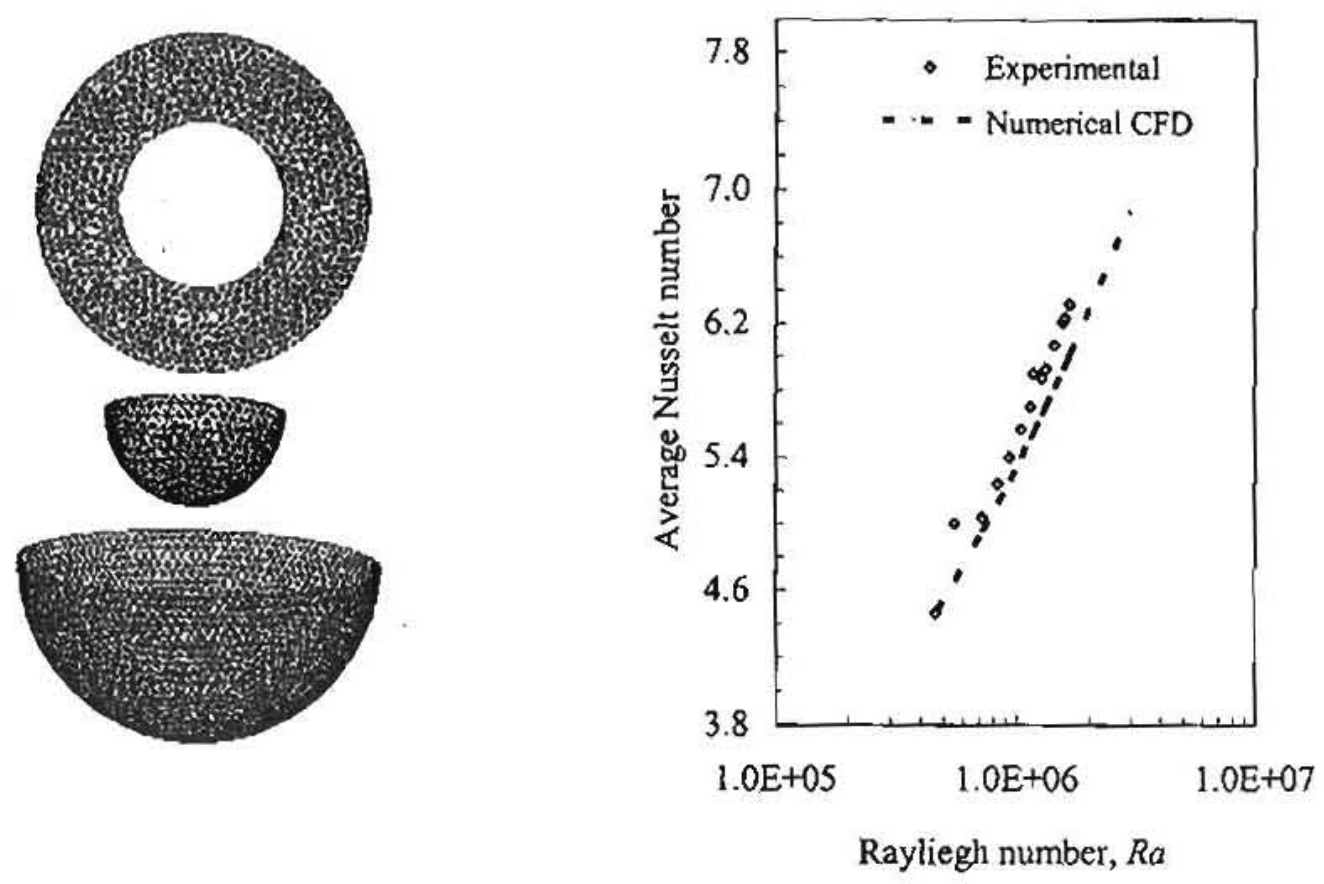

Figure (18), Tetrahedral grids on the surface of the two hemi-spheres and the meridian ellipse.

Figure (19), Verification of numerical CFD results with those from experimental tests.

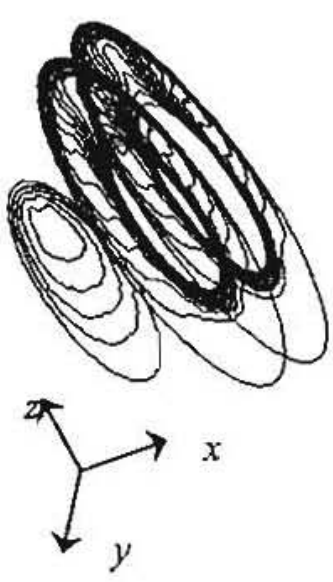

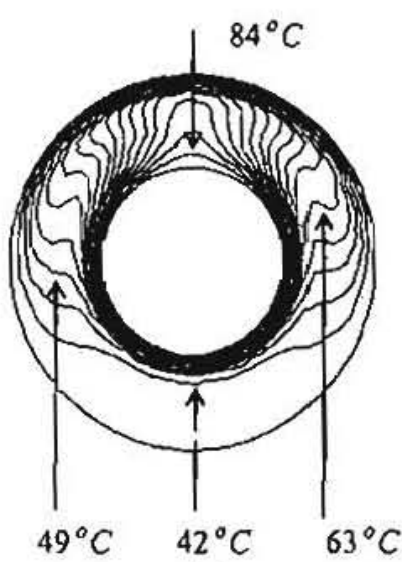

(a)
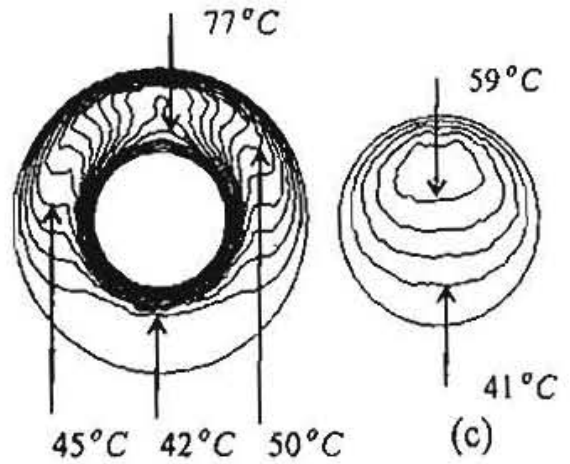

(c)

(b)

Figure (20), Temperature contours on three successive surfaces along the $x$-direction, (a) $x=0$, (b) $x=-3.75 \mathrm{~cm}$ and (c) $x=-9 \mathrm{~cm}$. 

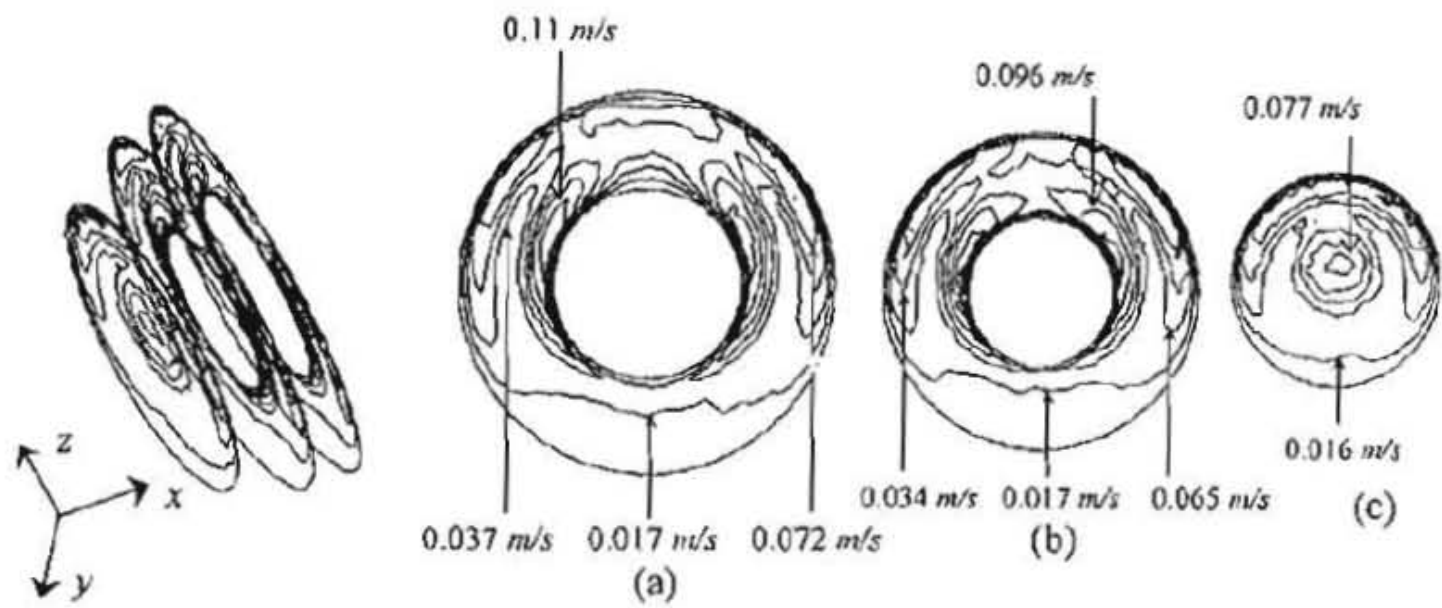

Figure (21), Velocity magnitude contours on three successive surfaces along the $x$-direction, (a) $x=0$, (b) $x=-3.75 \mathrm{~cm}$ and (c) $x=-9 \mathrm{~cm}$
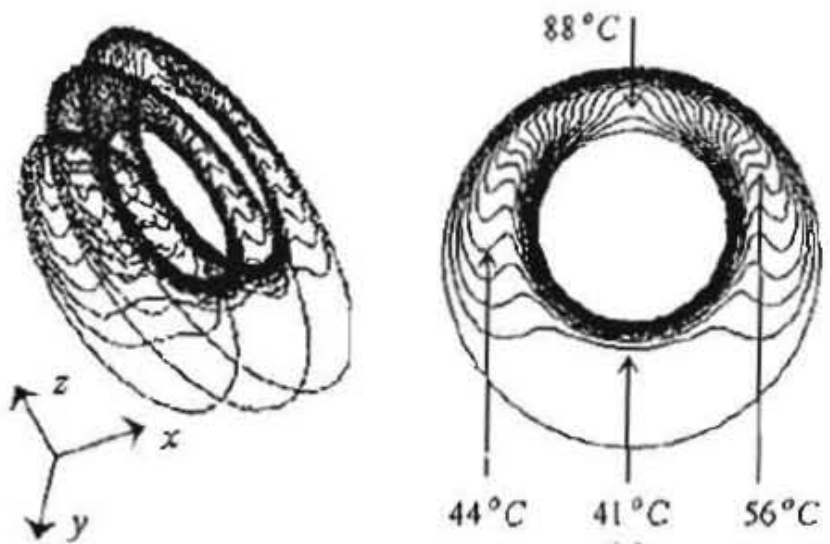

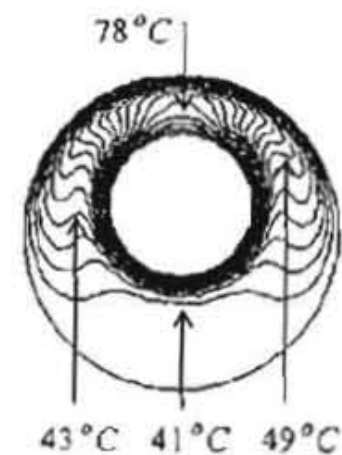

(b)

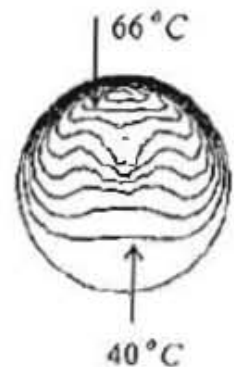

(c)

(a)

Figure (22), Temperature contours on threc successive surfaces along the $x$-direction for two ecccutric spheres with an eccentric distance of $2.5 \mathrm{~cm}$,

(a) $x=0$, (b) $x=-3.75 \mathrm{~cm}$ and (c) $x=.9 \mathrm{~cm}$.
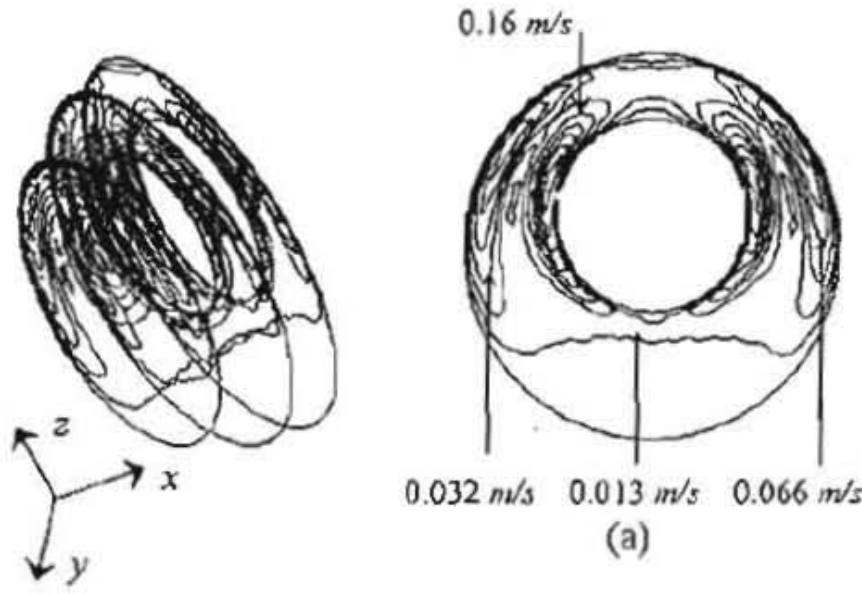

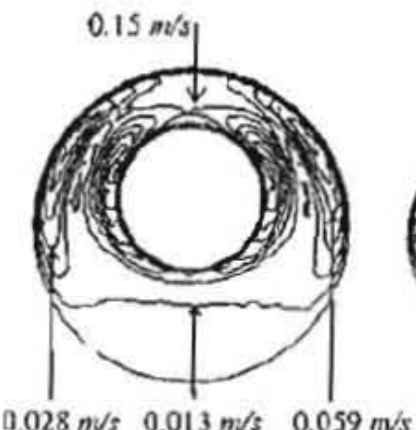

(b)

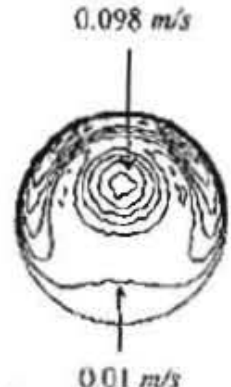

(c)

Figure (23), Velocity magnitude contours on three successive surfaces along the $x$-direction for two eccentric spheres with an eccentric distance of $2.5 \mathrm{~cm}$,

(a) $x=0$, (b) $x=-3.75 \mathrm{~cm}$ and (c) $x=-9 \mathrm{~cm}$. 


\section{84 El-Desouki Ibrahim Eid}

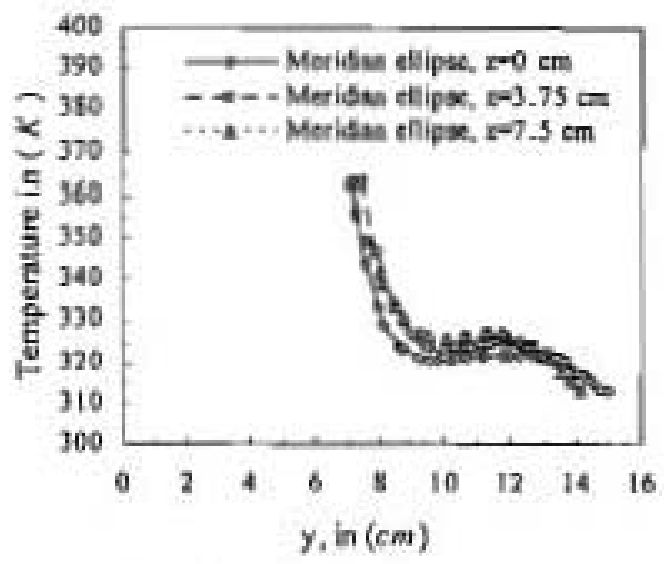

Figure (24), Temperature versus $y$-axis in the meridian ellipse at three local $z$-levels for two eccentric hemi-spheres $(e=2.5 \mathrm{~cm})$.

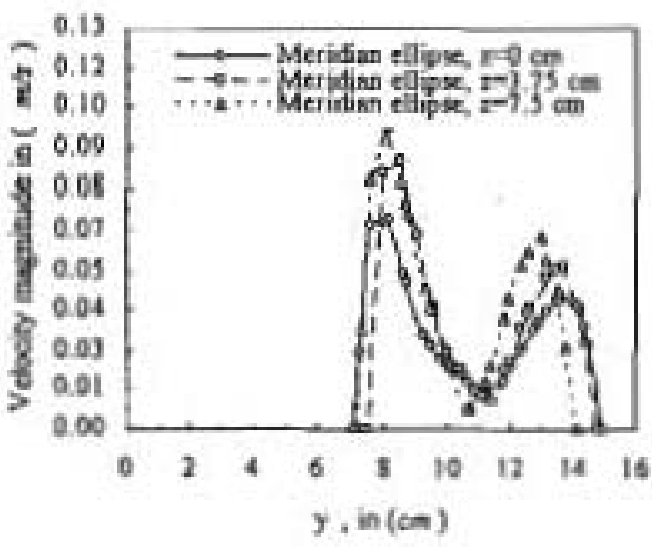

Figure (25), Velocity magnitude versus $y$ in the meridian ellipse at three $z$-levels for two eccentric hemi-spheres $(e-2.5 \mathrm{~cm})$.

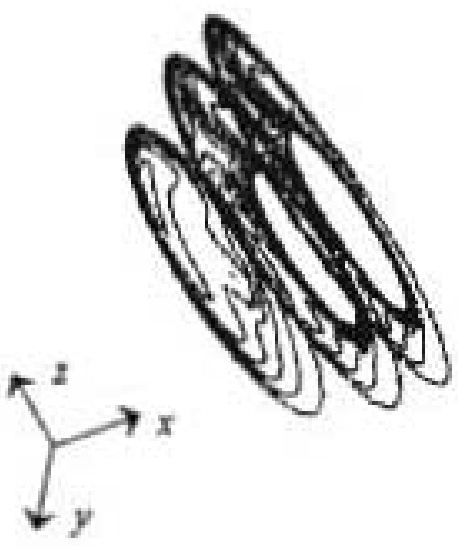

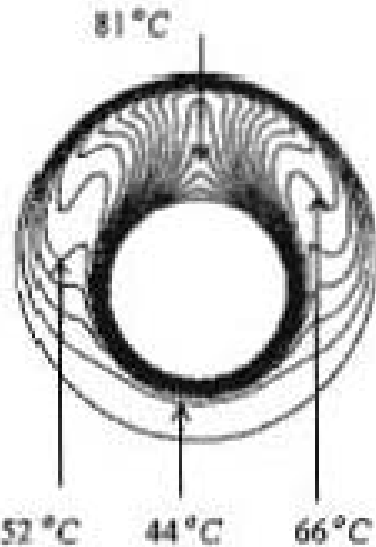

(a)

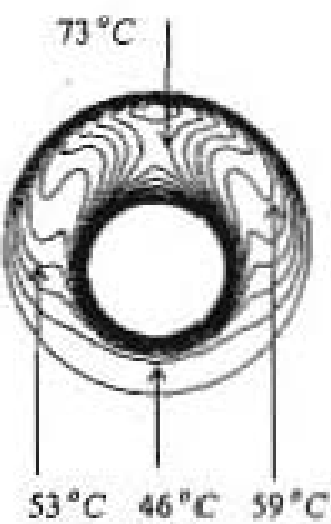

(b)

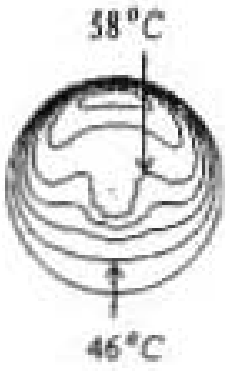

(c)

Figure (26), Temperature contours on three successive surfaces along the $x$-direction for two eccentric spheres with an eccentric distance of $(-2.5 \mathrm{~cm})$,

(a) $x=0$, (b) $x=-3.75 \mathrm{~cm}$ and (c) $x=-9 \mathrm{~cm}$.

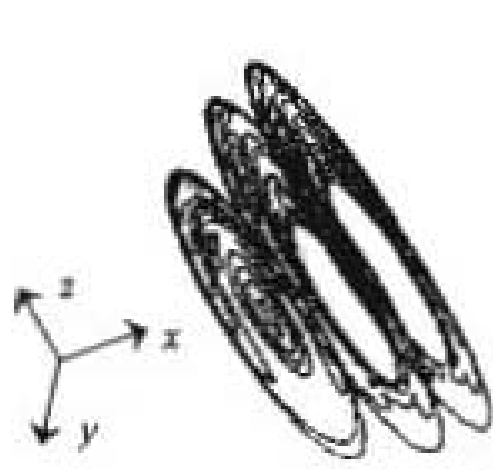

$0.041 \mathrm{~m} / \mathrm{s} \quad 0.018 \mathrm{~m} / \mathrm{s} \quad 0.081 \mathrm{~m} / \mathrm{s}$

(a)

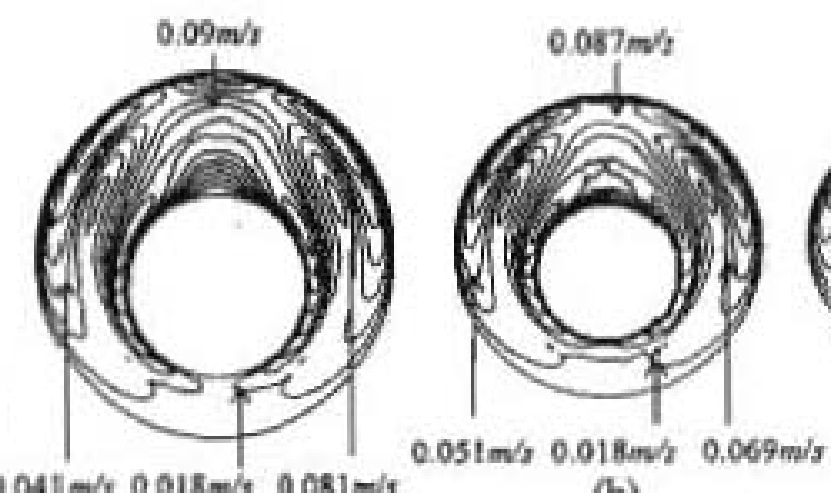

(b)

Figure (27), Velocity magnitude contours on three successive surfaces along the $x$-direction for two eccentric spheres with an eccentric distance of $(-2.5 \mathrm{~cm})$,

(a) $x=0$, (b) $x=-3.75 \mathrm{~cm}$ and (c) $x=-9 \mathrm{~cm}$. 


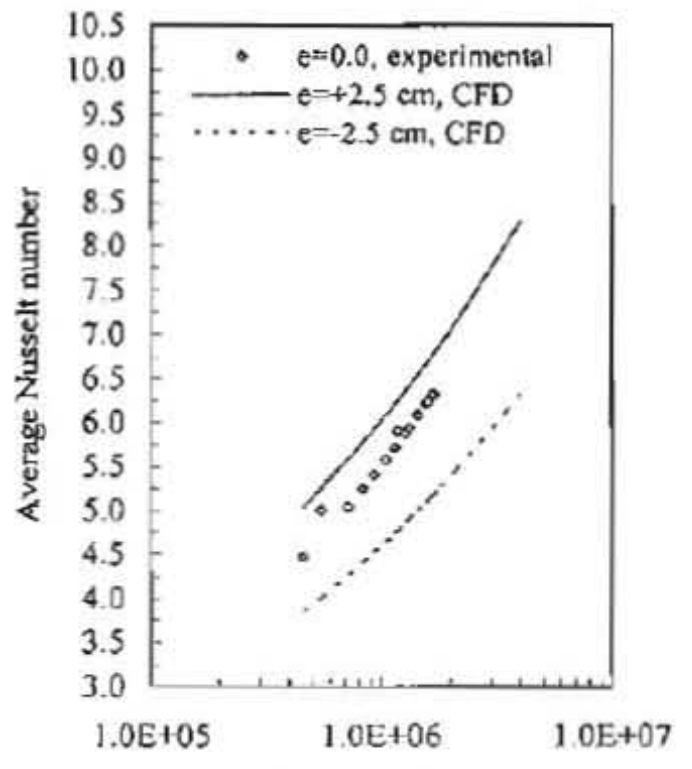

Rayliegh number, Ra

Figure (28), Average Nusselt number versus Rayliegh number for eccentric pair of hemisphere oriented vertically.
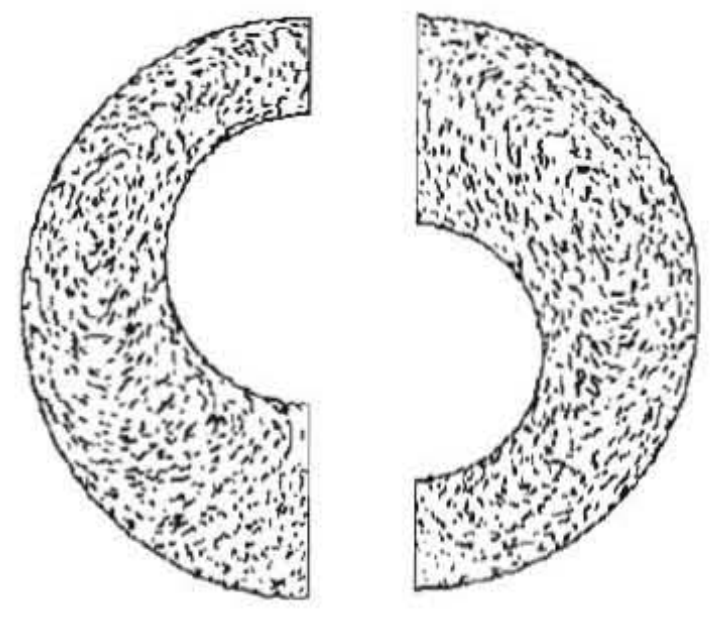

Figure (29), Path lines of air velocity in a twoplanes of both positive and negative cccentricities where $x=-2.5 \mathrm{~cm}$.

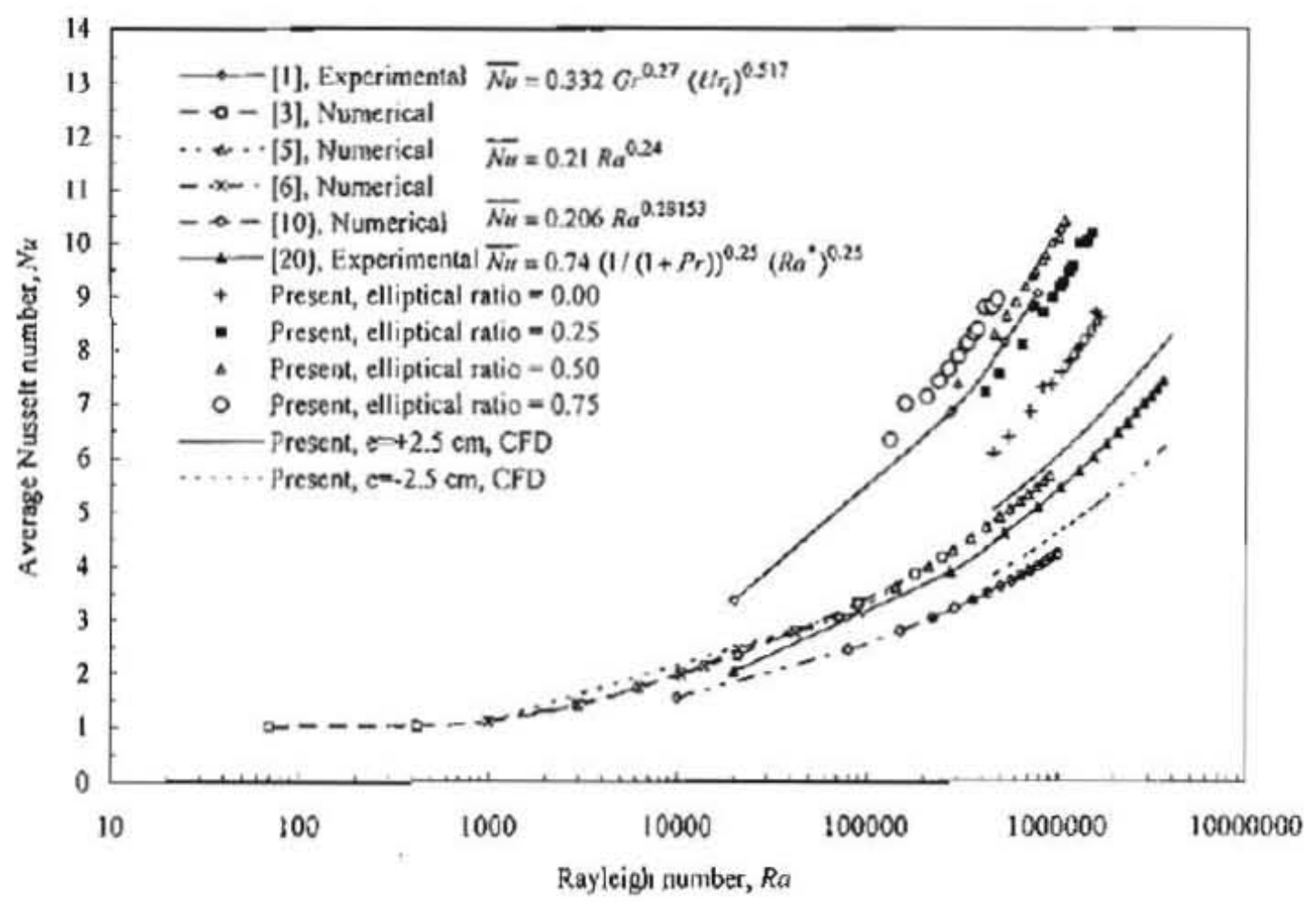

Figurc (30), Comparison among results of present attempt and those by the literatures. 